\title{
Hepatitis B Virus-related Immune Reconstitution Inflammatory Syndrome in Two Patients Coinfected with Human Immunodeficiency Virus Diagnosed with a Liver Biopsy
}

\author{
Fujiko Mitsumoto ${ }^{1}$, Masayuki Murata ${ }^{1}$, Yoshifumi Kato ${ }^{1}$, Kazuya Ura ${ }^{1}$, Koji Takayama ${ }^{1}$, \\ Satoshi Hiramine ${ }^{1}$, Hiroaki Ikezaki ${ }^{1}$, Motohiro Shimizu ${ }^{1}$, Kazuhiro Toyoda ${ }^{1}$, Eiichi Ogawa ${ }^{1}$, \\ Shinichi Aishima ${ }^{2}$, Norihiro Furusyo ${ }^{1}$ and Jun Hayashi ${ }^{3}$
}

\begin{abstract}
Hepatic flares occurred in two patients with HBV/HIV coinfection following the commencement of antiretroviral therapy (ART). At that time, the HIV RNA and HBV DNA levels had decreased. The results of liver biopsies showed lymphocytic infiltration that was diffusely positive for $\mathrm{CD} 8^{+} \mathrm{T}$ cells in the portal areas and lobules. These findings suggested HBV-related immune reconstitution inflammatory syndrome (IRIS). The alanine aminotransferase levels of both patients gradually decreased with the continuation of ART. Because there are few reports of the liver histology of HBV-related IRIS, these cases provide a better understanding of the pathogenesis of HBV-related IRIS.
\end{abstract}

Key words: hepatitis B virus, human immunodeficiency virus, immune reconstitution inflammatory syndrome, liver biopsy

(Intern Med 53: 2165-2170, 2014)

(DOI: 10.2169/internalmedicine.53.2503)

\section{Introduction}

Coinfection with hepatitis B virus (HBV) and human immunodeficiency virus (HIV) is common, primarily due to the shared routes of transmission. It is estimated that approximately $10 \%$ of patients with HIV infection worldwide are chronically coinfected with HBV (1). In Japan, HBV/ HIV coinfection has been reported in approximately $6 \%$ of patients with HIV infection (2). The current guidelines regarding the treatment of HIV infection recommend that patients with HBV/HIV coinfection receive antiretroviral therapy (ART) with activity against HBV, regardless of the number of $\mathrm{CD}^{+} \mathrm{T}$ cells. However, it has been reported that hepatic flares [defined as an alanine aminotransferase (ALT) level $>5$ times the upper limit of normal or $>100 \mathrm{IU} / \mathrm{L}$ higher than that observed at baseline] frequently occur in patients with HBV/HIV coinfection after the start of ART due to numerous causes, including opportunistic infections, the use of new hepatotoxic medications, excessive alcohol consumption and the development of immune reconstitution inflammatory syndrome (IRIS). Although liver biopsies are helpful for elucidating the cause of hepatic flares, there are few reports concerning the pathological findings of such biopsies in this patient population. We herein report two cases of HBV/HIV coinfection in which hepatic flares were observed following the commencement of ART. These flares were thought to reflect HBV-related IRIS based on the patients' clinical and liver biopsy findings.

${ }^{1}$ Department of General Internal Medicine, Kyushu University Hospital, Japan, ${ }^{2}$ Department of Anatomic Pathology, Graduate School of Medical Sciences, Kyushu University, Japan and ${ }^{3}$ Kyushu General Medicine Center, Haradoi Hospital, Japan

Received for publication January 17, 2014; Accepted for publication March 12, 2014

Correspondence to Dr. Masayuki Murata, mmurata@gim.med.kyushu-u.ac.jp 

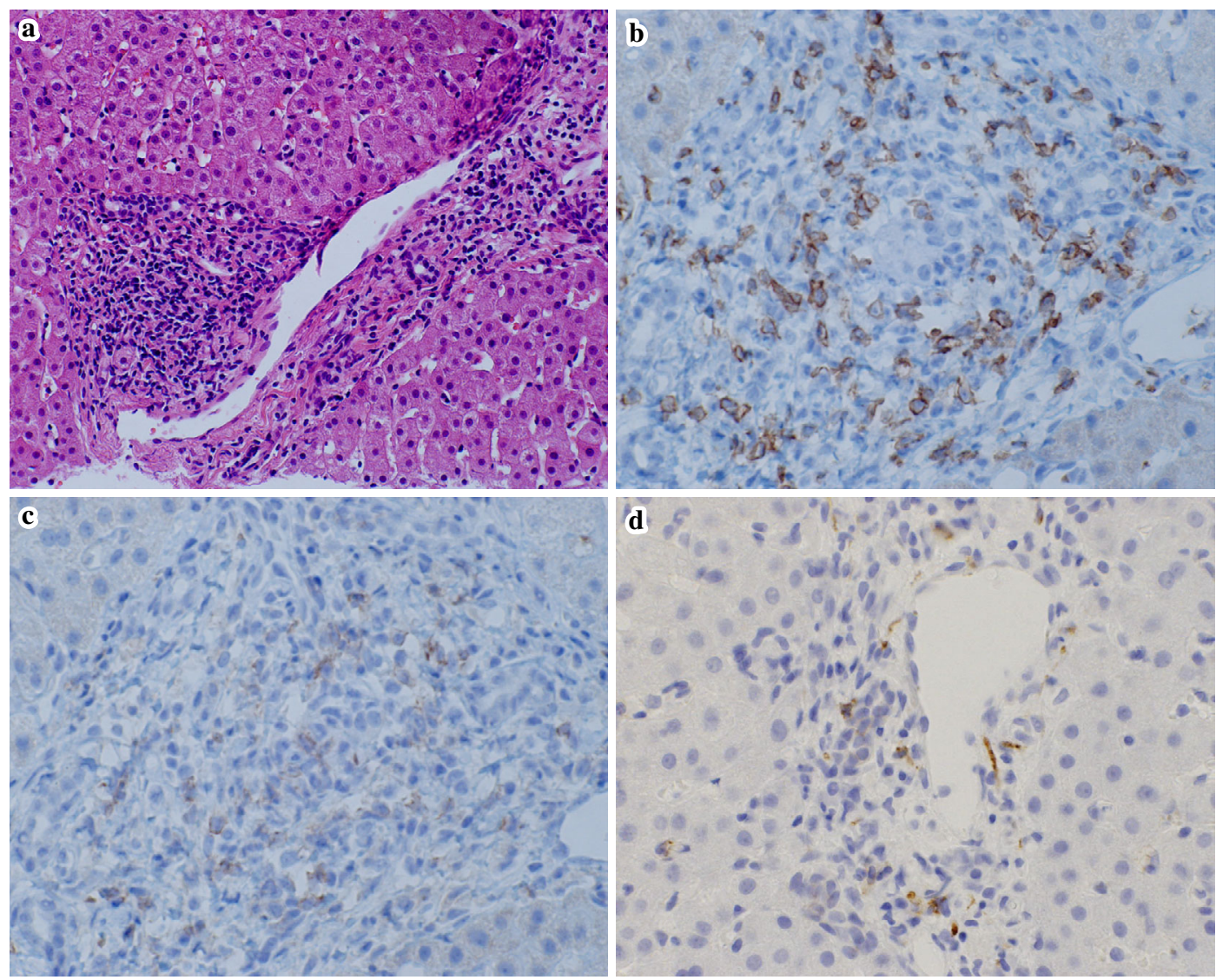

Figure 1. Histopathological findings of the first patient obtained at the time of the hepatic flare. a: The biopsy results revealed mild chronic inflammation in the enlarged portal areas (Metavir score, A1, F0) (Hematoxylin and Eosin staining, $\times 200$ ). b: The infiltrating lymphocytes were diffusely positive for CD8 on immunohistochemical staining $(\times 400)$. c: The CD4-positive cells were focal $(\times 400)$. d: Few CD56-positive cells were noted $(\times 400)$.

\section{Case Reports}

\section{Case 1}

A 30-year-old bisexual Japanese man with HBV/HIV coinfection developed a perianal abscess, stomachache, diarrhea and hematochezia over the seven months before his initial visit. He also experienced weight loss of $7 \mathrm{~kg}$ within the past year. Colonoscopy demonstrated that he was suffering from amoeba and cytomegalovirus (CMV) enterocolitis, as confirmed by the pathologic findings of the colon. Following the diagnosis of HBV and HIV coinfection, he was referred to our hospital for treatment of the enterocolitis and HBV/HIV coinfection. On admission, the patient was found to be positive for HIV-1 on a Western blot analysis, with an HIV RNA load of $4.4 \times 10^{5}$ copies $/ \mathrm{mL}$. The $\mathrm{CD}^{+}$and $\mathrm{CD} 8^{+}$ $\mathrm{T}$ cell counts were 19 and $286 / \mu \mathrm{L}$, respectively, while the aspartate aminotransferase (AST) and ALT levels were both within the normal limits (19 and $27 \mathrm{IU} / \mathrm{L}$, respectively). Hepatitis B surface antigens (HBsAg) were positive. Hepatitis $\mathrm{B}$ e antigens $(\mathrm{HBeAg})$ were positive ( $>1,600$ C.O.I), whereas antibodies to $\mathrm{HBeAg}$ were negative. In addition, IgM antibodies against hepatitis B core antigens (anti-HBc
IgM) were negative. The plasma HBV DNA level was more than $9.53 \log$ copies $/ \mathrm{mL}$, and the HBV genotype was A. Both antibodies to hepatitis $\mathrm{C}$ virus (HCV) and hepatitis A virus were negative. Anti-Entamoeba histolytica IgG antibodies were positive. CMV antigenemia was observed (C7HRP: 27/80,200 cells). Metronidazole and ganciclovir were administered to treat the amoeba and CMV colitis, while sulfamethoxazole/trimethoprim and azithromycin hydrate were prescribed to prevent pneumocystis pneumonia and disseminated mycobacterium infection, respectively. Furthermore, treatment with alprazolam and lormetazepam was started because the patient developed depression and insomnia after receiving the diagnosis of HIV infection. Because a colonoscopy re-examination showed a prominent improvement in the colonic ulcers 18 days later, the dose of metronidazole was discontinued, and ganciclovir was changed to valganciclovir as maintenance therapy for CMV colitis. Accordingly, ART was started with raltegravir (RAL) and tenofovir disoproxil fumarate/emtricitabine (TDF/FTC), as indicated for HBV and HIV coinfection. At that time, the ALT level was slightly elevated at $40 \mathrm{IU} / \mathrm{L}$ (normal range: 6-30 IU/L), although the AST and bilirubin levels were still normal, at $24 \mathrm{IU} / \mathrm{L}$ and $0.4 \mathrm{mg} / \mathrm{dL}$, respectively. Six weeks after the initiation of ART, the AST and ALT levels became 


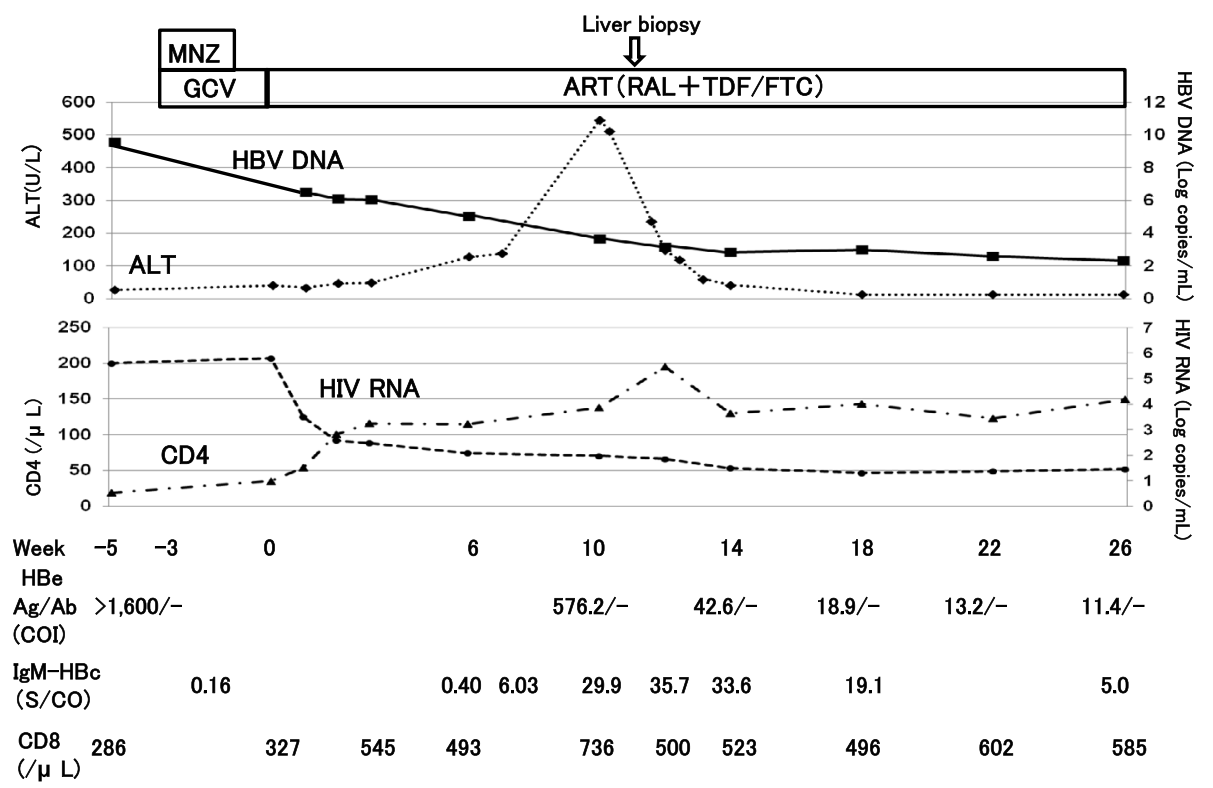

Figure 2. Clinical course of Case 1. MNZ: metronidazole, GCV: ganciclovir, ART: antiretroviral therapy, RAL: raltegravir, TDF: tenofovir disoproxil fumarate, FTC: emtricitabine

elevated (AST: 72 IU/L, ALT: 127 IU/L). Ten weeks after the start of ART, the AST level had increased to $280 \mathrm{IU} / \mathrm{L}$, while the ALT level had increased to $546 \mathrm{IU} / \mathrm{L}$. The total bilirubin level remained normal at $0.6 \mathrm{mg} / \mathrm{dL}$, and the prothrombin time was 12.8 seconds (INR: $1.09,81 \%$ ). Due to the administration of ART, the HIV RNA level decreased to 93 copies $/ \mathrm{mL}$ and the $\mathrm{CD}^{+}$and $\mathrm{CD}^{+} \mathrm{T}$ cell counts increased from 19 to 138 cells $/ \mu \mathrm{L}$ and 286 to 736 cells $/ \mu \mathrm{L}$, respectively. Meanwhile, the HBV DNA level had decreased from $>9.53$ to $3.63 \mathrm{log}$ copies $/ \mathrm{mL}$, and anti-HBc IgM were strongly positive (29.9 S/CO). No CMV antigenemia or eosinophilia was observed, and antinuclear antibodies were negative. The patient was a non-drinker and had not taken any additional medications. The appearance of the liver, as noted on ultrasonography, was normal. Because the cause of the hepatic flare was unknown, a liver biopsy was performed, the results of which showed mild chronic inflammation in the enlarged portal areas (A1, F0). Scattered singlecell necrosis and mild lobular hepatitis were also observed; however, no interface hepatitis or bridging fibrosis was evident, and no CMV-related nuclear inclusions or CMVpositive cells were found. Infiltrating lymphocytes were diffusely positive for $\mathrm{CD} 3$ and $\mathrm{CD} 8$, whereas $\mathrm{CD} 4^{+}$cells were focal, and few $\mathrm{CD} 56^{+}$cells were detected. Such observations have been reported as being compatible with a diagnosis of HBV infection, thus they were unlikely to be the result of drug-induced liver injury (Fig. 1). The patient's clinical, laboratory and histological findings therefore suggested HBV-related IRIS rather than drug hepatotoxicity. Because his general condition was good despite the liver enzyme elevation, his medication regimen, including ART was continued. Subsequently, the AST and ALT levels gradually decreased to normal 18 weeks after the start of ART (Fig. 2). Eighteen months after the initiation of ART, HBeAg were negative and HBV DNA was undetectable.

\section{Case 2}

A 20-year-old Japanese man with HBV infection was diagnosed with condyloma acuminatum and rectal carcinoids. A preoperative screening test found HIV infection, and the patient was referred to our hospital for the treatment of HBV/HIV coinfection. On his first visit, he was found to be positive for HIV-1 on a Western blot analysis, and his HIV RNA load was $8.7 \times 10^{4}$ copies $/ \mathrm{mL}$. The $\mathrm{CD}^{+}$and $\mathrm{CD}^{+} \mathrm{T}$ cell counts were 484 and $735 / \mu \mathrm{L}$, respectively. The AST and ALT levels were slightly increased at 54 and 77 IU/L, respectively. HBsAg and $\mathrm{HBeAg}$ (>1,600 C.O.I) were both positive, whereas antibodies to $\mathrm{HBeAg}$ were negative. The plasma HBV DNA level was $9.22 \log$ copies $/ \mathrm{mL}$, and the HBV genotype was A. The degree of liver stiffness was 8.8 $\mathrm{kPa}$, as measured on transient elastography (FibroScan, Echosens, Paris, France). Because the number of $\mathrm{CD}^{+} \mathrm{T}$ cells continued to be high, he was given pegylatedinterferon (IFN) $\alpha-2 \mathrm{a}$ for chronic $\mathrm{HBV}$ infection. However, the HBV DNA level did not decrease, and no seroconversion of $\mathrm{HBeAg}$ was noted during this period. Treatment with ART was therefore started with RAL and TDF/FTC. At that time, the AST and ALT levels were both within the normal limits (29 and 23 IU/L, respectively). However, elevated levels of AST and ALT were observed 25 weeks after the initiation of ART (AST: 326 IU/L, ALT: $168 \mathrm{IU} / \mathrm{L}$ ), and at 27 weeks, the AST level increased to $206 \mathrm{IU} / \mathrm{L}$, while the ALT level increased to $389 \mathrm{IU} / \mathrm{L}$. In contrast, the total bilirubin level and prothrombin time remained within the normal limits. Following the administration of ART, the HIV RNA level decreased to less than 20 copies $/ \mathrm{mL}$, although the $\mathrm{CD}^{+}$and $\mathrm{CD}^{+} \mathrm{T}$ cell counts did not change (441 cells $/ \mu \mathrm{L}$ and 465 cells $/ \mu \mathrm{L}$, respectively). The HBV DNA level decreased from 9.22 to $2.56 \log$ copies $/ \mathrm{mL}$, and anti-HBc IgM were negative. The appearance of the liver, as 

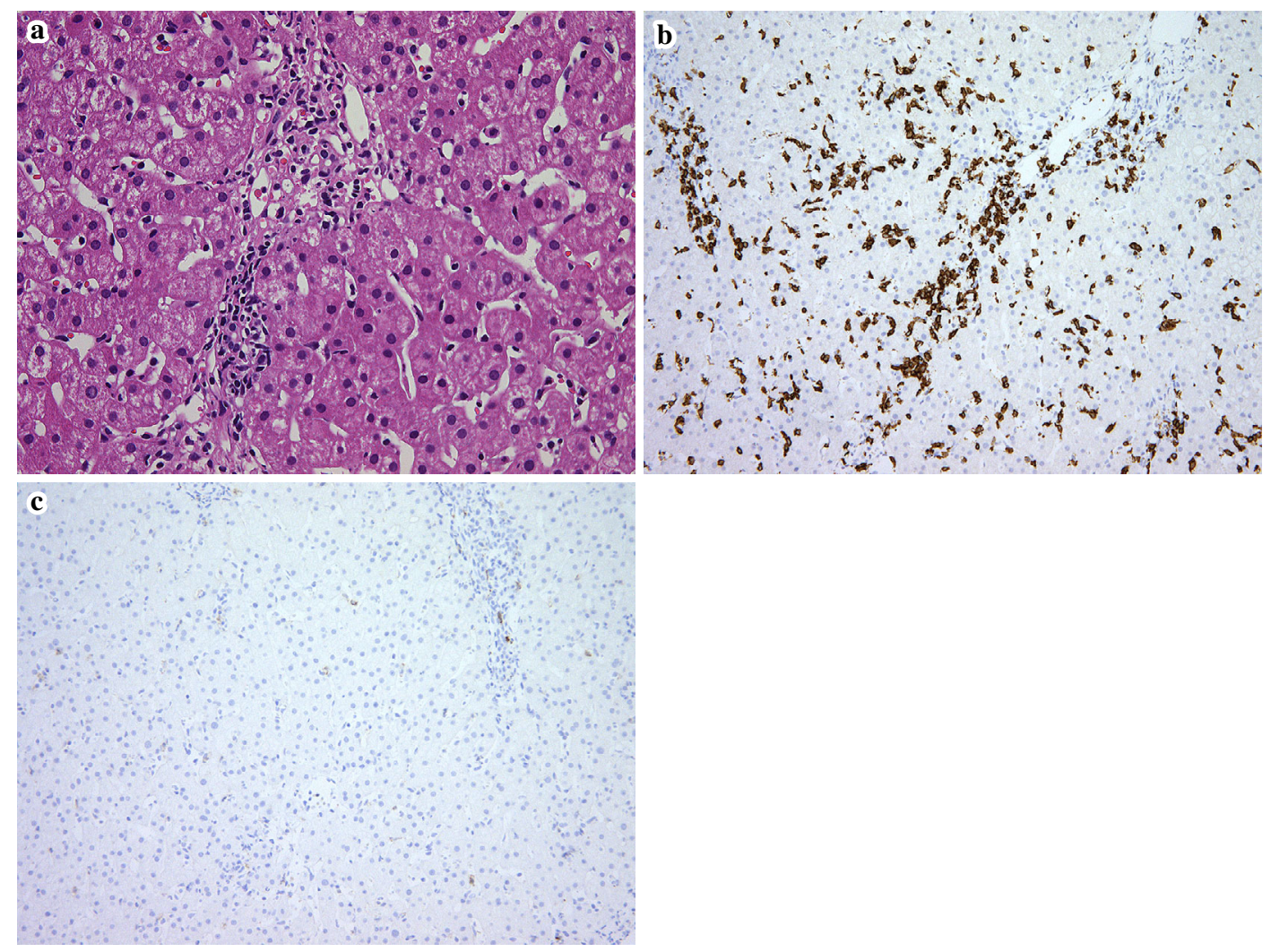

Figure 3. Histopathological findings of the second patient obtained at the time of the hepatic flare. a: The biopsy results revealed mild lymphocytic infiltration in the portal areas and lobules (Metavir score, A1F0) (Hematoxylin and Eosin staining, $\times 200$ ). b: Infiltrating lymphocytes were diffusely positive for CD8 on immunohistochemical staining $(\times 100)$. c: The CD56-positive cells were focal $(\times 100)$.

observed on ultrasonography, was normal. The patient's general condition was good. He underwent a liver biopsy to elucidate the cause of the hepatic flare, and the results of the biopsy showed mild lymphocytic infiltration in the portal areas and lobules. In addition, scattered single-cell necrosis and mild lobular hepatitis were observed. Infiltrating lymphocytes were diffusely positive for CD3 and CD8 but negative for CD20 and CD56. These features indicated a diagnosis of chronic hepatitis, likely related to the HBV (A1, F0), rather than drug-induced liver injury (Fig. 3). The patient's clinical, laboratory and histological findings suggested HBV-related IRIS, and the ART regimen was continued. Subsequently, the AST and ALT levels gradually decreased, as did the titer of HBeAg (Fig. 4).

\section{Discussion}

We herein reported two cases of HBV/HIV coinfection in which hepatic flares were observed following the commencement of ART. Both cases were thought to involve HBV-related IRIS based on the patients' clinical and liver biopsy findings.

It has been reported that $20-25 \%$ of patients with $\mathrm{HBV} /$ HIV coinfection experience HBV-related IRIS after the start of ART $(3,4)$. The introduction of ART results in the reconstitution of various $\mathrm{HBV}$-specific $\mathrm{CD}^{+}$and $\mathrm{CD}^{+} \mathrm{T}$ cell re- sponses in association with restoration of the $\mathrm{CD}^{+} \mathrm{T}$ cell count (5). It is considered that the hepatic flares of patients with chronic HBV infection alone occur secondary to the recruitment of both $\mathrm{HBV}$-specific $\mathrm{CD}^{+} \mathrm{T}$ cells and non-HBV specific mononuclear cells to the liver, a process that is primarily mediated by proinflammatory and antiviral cytokines, such as tumor necrosis factor (TNF)- $\alpha$ and IFN- $\gamma$ (6-8). However, it is currently unclear whether the immunopathogenesis of HBV-related IRIS observed in patients with $\mathrm{HBV} / \mathrm{HIV}$ coinfection is the same as that underlying the hepatic flares of patients with HBV infection alone. The pathological findings of the liver in the present cases are summarized in Table. These findings revealed the presence of lymphocytic infiltrates in the portal areas and lobules. The infiltrating lymphocytes were diffusely positive for CD3 and CD8, although CD4-positive cells were focal, and few CD56-positive cells were detected. This liver histology is similar to that of the hepatic flares seen in patients with chronic HBV infection alone, and no differences between these features were found in our two patients.

A previous study of cytokines and chemokines reported that the occurrence of hepatic flares in patients with HBV infection alone is associated with the production of IFN- $\alpha$ and interleukin (IL)-8, which leads to the recruitment of activated TNF-related apoptosis-inducing ligand (TRAIL)expressing NK cells to the liver, with and subsequent hepa- 


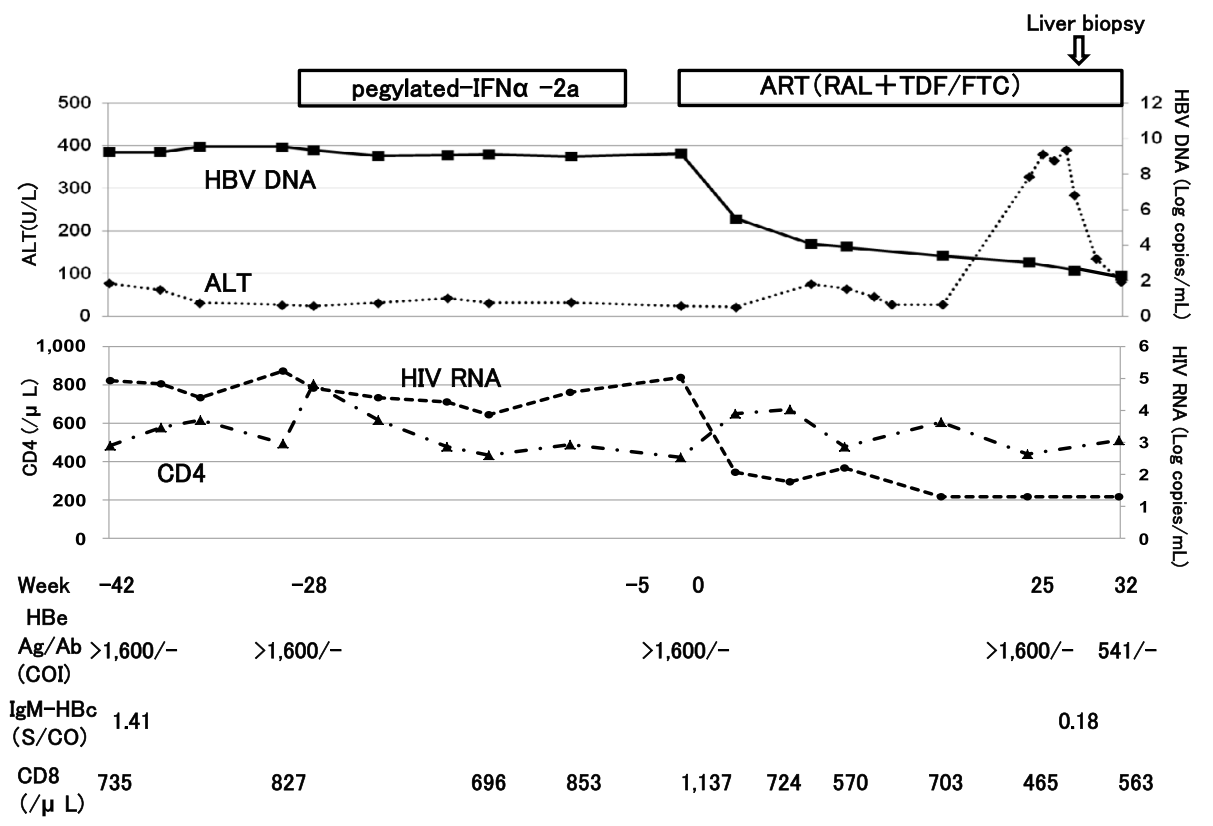

Figure 4. Clinical course of Case 2. ART: antiretroviral therapy, RAL: raltegravir, TDF: tenofovir disoproxil fumarate, FTC: emtricitabine

Table. Summary of the Histopathological Findings of the Liver

\begin{tabular}{lll}
\hline & Hematoxylin and Eosin staining & Immunohistochemical staining \\
\hline Case 1 & - Chronic hepatitis, A1, F0. & $\cdot$ Diffusely positive for CD3 and CD8. \\
& (Mild lymphocytic inflammation in the & $\cdot$ Focally positive for CD4. \\
& enlarged portal areas) & $\cdot$ CD 56 positive cells are few. \\
& - Single cell necrosis and mild lobular & \\
& hepatitis are scattered. & \\
& - Interface hepatitis and bridging fibrosis & \\
are not evident. & \\
& - Chronic hepatitis, A1, F0. & $\cdot$ Diffusely positive for CD3 and CD8. \\
Case 2 & Mild lymphocytic inflammation in the & $\cdot$ Focally positive for CD4. \\
& portal areas and lobules) & $\cdot$ Negative for CD20 and CD56. \\
& - Single cell necrosis and mild lobular & \\
hepatitis are few. & \\
& - Interface hepatitis and bridging fibrosis & \\
are not evident.
\end{tabular}

tocyte damage (9). A recent report showed that increased plasma levels of CXCL-10 and soluble CD30 are associated with hepatic flares in patients with $\mathrm{HBV} / \mathrm{HIV}$ coinfection (10). CXCL-10 is a chemoattractant for $\mathrm{T}$ cells, NK cells and monocytes to the liver, and persistent elevation of the CXCL-10 level in the setting of a rising $\mathrm{CD}^{+} \mathrm{T}$ cell count may therefore drive enhanced $\mathrm{T}$ cell recruitment to the liver. However, in contrast to the findings for hepatic flares in patients with $\mathrm{HBV}$ infection alone, no clear associations have been detected between TRAIL-expressing NK cells and HBV-related IRIS in patients with HBV/HIV coinfection. Therefore, the immunopathogenesis of HBV-related IRIS in HIV-coinfected patients appears to be different from that underlying the hepatic flares seen in patients with HBV infection alone. However, further studies including more patients are needed to confirm these findings.

Both of our patients were asymptomatic at the time of HBV-related IRIS onset, and their ALT levels decreased in association with the continuation of ART. The first patient exhibited seroconversion of $\mathrm{HBeAg} 16$ months after the onset of HBV-related IRIS. In addition, the HBeAg titer in the second patient began to decrease after the hepatic flare. In cases of HBV-related IRIS, ART may be continued under close monitoring of the hepatic function, as the onset of IRIS may be followed by seroconversion of $\mathrm{HBeAg}$ or HBsAg (11).

Generally, patients who develop IRIS have a low $\mathrm{CD}^{+} \mathrm{T}$ cell count $(<50$ cells $/ \mu \mathrm{L})$ and high HIV RNA level at the commencement of ART. The Avihingsanon group showed that hepatic flares that seem to reflect HBV-related IRIS are observed at a median of 56 days (3). However, in the present case 2, the hepatic flare was observed 25 weeks after the start of ART, and the patient's $\mathrm{CD}^{+} \mathrm{T}$ cell count was greater than 400 cells $/ \mu \mathrm{L}$ prior to the initiation of ART. The second case was atypical for HBV-related IRIS. This may be due to the immunomodulatory effects of pegylated-IFN $\alpha-2 \mathrm{a}$ therapy observed before the start of ART. It is well known that IFN has an immunomodulatory effect in addition to its 
antiviral actions, and some patients with HBV infection experience $\mathrm{HBeAg}$ or $\mathrm{HBsAg}$ seroclearance after the end of IFN treatment (12-14). We speculate that IFN may have influenced the patient's immune response to HBV. For example, when his HBV DNA and HIV RNA levels decreased after the start of ART, his cellular immune response to HBV was reconstituted by treatment with IFN and ART. Therefore, he may have developed the hepatic flare as a form of HBV-related IRIS despite his $\mathrm{CD}^{+} \mathrm{T}$ cell count being more than 400 cells $/ \mu \mathrm{L}$ prior to the initiation of ART. Furthermore, according to previously described criteria for IRIS issued by the International Network for the Study of HIVassociated IRIS (INSHI) and the AIDS Clinical Trials Group (ACTG), data regarding the $\mathrm{CD}^{+} \mathrm{T}$ cell count at the commencement of ART and its improvement are not necessary for a diagnosis of IRIS, although there is no universally accepted definition for the condition $(15,16)$.

In conclusion, conducting a liver biopsy is helpful for elucidating the cause of hepatic flares following the commencement of ART. If a hepatic flare is thought to be due to HBV-related IRIS, treatment with ART can be continued. HBV-related IRIS occurs in the recovery process of immunocompetence, and its pathological findings are similar to those of the hepatic flare seen in patients with HBV infection alone. Because there are few reports of the liver histology of patients with HBV-related IRIS, our cases may have implications with respect to improving knowledge regarding the pathogenesis of HBV-related IRIS.

The authors state that they have no Conflict of Interest (COI).

\section{References}

1. Soriano V, Puoti M, Peters M, et al. Care of HIV patients with chronic hepatitis $\mathrm{B}$ : updated recommendations from the HIVHepatitis B Virus International Panel. AIDS 22: 1399-1410, 2008.

2. Koike K, Kikuchi Y, Kato M, et al. Prevalence of hepatitis B virus infection in Japanese patients with HIV. Hepatol Res 38: 310-314, 2008.

3. Avihingsanon A, Matthews GV, Lewin SR, et al. Assessment of HBV flare in a randomized clinical trial in HIV/HBV coinfected subjects initiating HBV-active antiretroviral therapy in Thailand.
AIDS Res Ther 9: 6, 2012.

4. Andrade BB, Hullsiek KH, Boulware DR, et al. Biomarkers of inflammation and coagulation are associated with mortality and hepatitis flares in persons coinfected with HIV and hepatitis viruses. J Infect Dis 207: 1379-1388, 2013.

5. Lascar RM, Lopes AR, Gilson RJ, et al. Effect of HIV infection and antiretroviral therapy on hepatitis B virus (HBV)-specific $T$ cell responses in patients who have resolved HBV infection. J Infect Dis 191: 1169-1179, 2005.

6. Guidotti LG, Ishikawa T, Hobbs MV, Matzke B, Schreiber R, Chisari FV. Intracellular inactivation of the hepatitis B virus by cytotoxic T lymphocytes. Immunity 4: 25-36, 1996.

7. Maini MK, Boni C, Lee CK, et al. The role of virus-specific CD8 ${ }^{+}$ cells in liver damage and viral control during persistent hepatitis B virus infection. J Exp Med 191: 1269-1280, 2000.

8. Sprengers D, van der Molen RG, Kusters JG, et al. Different composition of intrahepatic lymphocytes in the immune-tolerance and immune-clearance phase of chronic hepatitis B. J Med Virol 78: 561-568, 2006.

9. Dunn C, Brunetto M, Reynolds G, et al. Cytokines induced during chronic hepatitis B virus infection promote a pathway for NK cell-mediated liver damage. J Exp Med 204: 667-680, 2007.

10. Crane M, Oliver B, Matthews $G$, et al. Immunopathogenesis of hepatic flare in HIV/hepatitis B virus (HBV)-coinfected individuals after the initiation of HBV-active antiretroviral Gtherapy. J Infect Dis 199: 974-981, 2009.

11. Matthews GV, Avihingsanon A, Lewin SR, et al. A randomized trial of combination hepatitis B therapy in HIV/HBV coinfected antiretroviral naïve individuals in Thailand. Hepatology 48: 10621069, 2008.

12. Niederau $C$, Heintges $T$, Lange $S$, et al. Long-term follow-up of $\mathrm{HBeAg}$-positive patients treated with interferon alfa for chronic hepatitis B. N Engl J Med 334: 1422-1427, 1996.

13. Lin SM, Tai DI, Chien RN, Sheen IS, Chu CM, Liaw YF. Comparison of long-term effects of lymphoblastoid interferon alpha and recombinant interferon alpha-2a therapy in patients with chronic hepatitis B. J Viral Hepat 11: 349-357, 2004.

14. Piratvisuth T, Lau G, Chao YC, et al. Sustained response to peginterferon alfa-2a $(40 \mathrm{kD})$ with or without lamivudine in Asian patients with $\mathrm{HBeAg}$-positive and $\mathrm{HBeAg}$-negative chronic hepatitis B. Hepatol Int 2: 102-110, 2008.

15. International Network for the Study of HIV-associated IRIS (INSHI). General IRIS Case Definition (Cited 2014 July 23). http://www.inshi.umn.edu/definitions/General_IRIS/home.html

16. AIDS Clinical Trials Group Network. Immune Reconstitution Inflammatory Syndrome Genetic Criteria (Revised 01/10/09) (Cited 2014 July 23). https://actgnetwork.org/IRIS_Case_Definitions

(C) 2014 The Japanese Society of Internal Medicine http://www.naika.or.jp/imonline/index.html 